\title{
STRUCTURAL FEATURES OF DIOXANE LIGNIN FROM Eucalyptus globulus AND THEIR RELATIONSHIP WITH THE PULP YIELD OF CONTRASTING GENOTYPES
}

\author{
María Graciela Aguayo ${ }^{1,2}$, José Ruiz ${ }^{2}$, Marcela Norambuena ${ }^{3}$, Regis Teixeira Mendonça ${ }^{1,2, \uparrow}$
}

\begin{abstract}
The chemical structure of dioxane lignins isolated from two groups of Eucalyptus globulus genotypes with contrasting pulpwood characteristics were evaluated. Six genotypes were selected and separated in two groups (G1 and G2) based on differences in wood density, pulp yield and chemical characteristics. Lignin was isolated from both milled wood and kraft pulps produced at kappa number 16, and were characterized by different techniques such as FTIR, elemental analysis, molar mass distribution and ${ }^{31} \mathrm{P}$ NMR spectroscopy. From the different characteristics evaluated, some were determined as more relevant, such as syringyl (S) and guaiacyl (G) amounts, S/G ratio and condensed biphenyl units, were correlated with the pulp yield. High correlations were found between pulp yield and syringyl units $\left(\mathrm{R}^{2}=0,69\right)$, and pulp yield and syringyl/guaicyl ratio $\left(\mathrm{R}^{2}\right.$ $=0,88)$. The condensed 5-5 biphenyl units presented a negative correlation with pulp yield $\left(\mathrm{R}^{2}=0,76\right)$. The information obtained explained part of the difference in pulpability of the contrasting genotypes and can be used for the selection and improvement of the species for the pulp and paper industry.
\end{abstract}

Keywords: Dioxane lignin, kraft pulping, Eucalyptus globulus, FTIR, ${ }^{31} \mathrm{P}$ NMR spectroscopy.

\section{INTRODUCTION}

The study of the characteristics of wood components and their effect during pulping processes is subject of several works (Pinto et al. 2002, 2005, Guerra et al. 2006, Ramirez et al. 2009, Aguayo et al. 2013). The characteristics of lignin are among the most important features for understanding the mechanisms of its removal from cell wall during chemical pulping processes. This information is useful not only for the wood of different species, but also for different genotypes of a single species, as found in commercial plantations for the pulp and paper industry. The present work will be focused on Eucalyptus wood that is an important raw material for the production of writing and printing paper and, specifically, Eucalyptus globulus that represents the main source of short fiber for countries like Chile, Spain, Portugal and Australia.

Structural characteristics of Eucalyptus lignin explained some advantages of this species when compared with other hardwoods during pulping and bleaching processes. For instance, Pinto et al. (2005), characterized by ${ }^{13} \mathrm{C}$ NMR spectroscopy lignins from different hardwood species. In Eucalyptus globulus, more than $80 \%$ of lignin units are syringyl-type, higher than the average found in other species as Eucalyptus grandis, Eucalyptus urograndis and Betula pendula, which showed S-type amounts between $65 \%$ and $70 \%$. After pulping, the relative content of S-units decreased, however, it still higher in Eucalyptus, while in the other wood species, the ${ }^{\circ}$-type units become predominant in the residual lignin, affecting bleaching performance. It was also showed that lignin in Eucalyptus globulus kraft pulps had lower condensation degree and high frequency of $\beta-\mathrm{O}-4$ linkages than other species.

\footnotetext{
Facultad de Ciencias Forestales, Universidad de Concepción, Casilla 160-C, Concepción, Chile.

${ }^{2}$ Centro de Biotecnología, Universidad de Concepción, Casilla 160-C, Concepción, Chile.

${ }^{3}$ BioEnercel S.A., Edificio IdeaIncuba, Universidad de Concepción, Concepción, Chile.

^Corresponding author: rteixeira@udec.cl

Received: 18.08.2014 Accepted: 27.02.2015
} 
However, there is less information if genotypes from a single species could also present significant differences in structural characteristics of lignin that can be relevant during pulping process. Guerra et al. (2008), showed that for different clones of Eucalyptus globulus, the lignin content did not correlated with the pulp yield, but significant correlations were found between pulp yield and the content of S- $\beta-O-4$ type structures. In a previous work, Aguayo et al. (2013), evaluated different Eucalyptus globulus genotypes that showed a significant variation in wood density and kraft pulp yield. Wood and pulp samples were analyzed by UV microspectrophotometric (UMSP) and thioacidolysis. Results showed that samples with the lowest lignin levels had also the lowest UV absorption at $278 \mathrm{~nm}$ in the secondary wall (0,22 A-units) and low levels of S-type $\beta$-O-4 linkages in the lignin structure. In samples obtained during kraft pulping, UV absorbance decreased reaching values as low as $0,08 \mathrm{~A}$-units. Samples with high levels of initial lignin, have significantly higher UV absorbance $\left(A_{278 \mathrm{~mm}} 0,15\right)$ and lignin enriched in G- $\beta-\mathrm{O}-4$ structures. These analyses performed in situ revealed that distribution of lignin in the cell wall and, at least one structural characteristic (abundance of $\mathrm{S}$ or $\mathrm{G}$ units), had important effect in kraft delignification and pulp yield.

To complement the previous study, the present work focused on the chemical and structural characterization of lignin extracted from wood and kraft pulps of selected genotypes of Eucalyptus globulus with the aim to determine the existence of other features that could also be associated with the pulping performance in this species.

\section{EXPERIMENTAL}

\section{Wood and pulp samples}

Eucalyptus globulus trees (15 years old) were sampled from a commercial plantation provided by a Chilean forest company located in the Biobío Province. Six genotypes were selected and separated in two groups (G1 and G2) based on a previous study that showed significant variations in wood density, pulp yield and chemical characteristics (Table 1) according to Aguayo et al. (2013). Logs of 35-40 cm were cut along the trunk from each tree. All the logs were visually examined to discard the presence of tension wood determined by pith asymmetry in the longitudinal axis of the log. Selected $\operatorname{logs}{ }^{\circ}$ were chipped and wood chips from each of the samples were submitted to kraft pulping in a rotary digester equipped with 4 independent 1,5-L vessels (Regmed Ltda., Brazil). Each vessel was loaded with $50 \mathrm{~g}$ of wood chips (dry basis) and $200 \mathrm{~mL}$ of cooking liquor with active alkali (AA) varying from $18,5 \%$ to $19,5 \%$ and $30 \%$ sulfidity (both calculated on dry wood basis and expressed as $\mathrm{NaOH}$ equivalents). Reactor heating rate was $2,1 \mathrm{oC} / \mathrm{min}$, cooking temperature was $165 \mathrm{oC}$ and the $\mathrm{H}$-factor used was 800 . Produced pulps were screened through a $0,2 \mathrm{~mm}$ slot screen and the screened pulp yield was determined. Kappa number was measured according to TAPPI Standard T236 om-99. 
Table 1. Wood and kraft pulps characteristics of Eucalyptus globulus genotypes.

\begin{tabular}{|l|ccc|ccc|}
\hline & \multicolumn{3}{|c}{ Group 1 } & \multicolumn{3}{c|}{ Group 2 } \\
& 1 & 2 & 3 & 4 & 5 & 6 \\
\hline Density (kg/m $\left.{ }^{3}\right)$ & 563 & 573 & 547 & 485 & 485 & 484 \\
Glucose (\%) & $53,8 \pm 0,5$ & $53,3 \pm 0,5$ & $52,1 \pm 0,5$ & $50,3 \pm 0,9$ & $49,2 \pm 0,7$ & $48,7 \pm 0,8$ \\
Xylans (\%) & $11,6 \pm 0,3$ & $11,6 \pm 0,7$ & $11,2 \pm 0,4$ & $13,1 \pm 0,6$ & $12,6 \pm 0,6$ & $14,3 \pm 0,7$ \\
Lignin (\%) & $23,8 \pm 0,5$ & $24,1 \pm 0,2$ & $24,9 \pm 0,1$ & $28 \pm 0,3$ & $27 \pm 0,5$ & $25,8 \pm 0,8$ \\
$\beta$-O-4 linkages (\%) & $60,2 \pm 0,4$ & $56,8 \pm 0,7$ & $58,4 \pm 0,9$ & $56,5 \pm 1,3$ & $51,3 \pm 1,1$ & $51,5 \pm 0,9$ \\
\hline Active alkali (\%) & 19 & 18,5 & 19 & 19,5 & 19,5 & 19 \\
Pulp yield (\%) & $58,4 \pm 0,6$ & $58,5 \pm 0,7$ & $58 \pm 0,6$ & $54,6 \pm 0,6$ & $56,4 \pm 1,6$ & $54,2 \pm 0,2$ \\
Kappa number & $15,7 \pm 0,2$ & $16,7 \pm 0,2$ & $15,6 \pm 0,6$ & $15,3 \pm 0,4$ & $15,6 \pm 0,2$ & $16,7 \pm 0,2$ \\
\hline
\end{tabular}

\section{Isolation of lignin from wood and pulps}

The isolation of the lignin from wood and pulps was based on the methodology described by Evtuguin et al. (2001), using mild acidolysis and dioxane as solvent. First, milled wood (40/60 mesh) was subjected to extractives removal with acetone (90\%) for $16 \mathrm{~h}$ in a Soxhlet apparatus. Further, extractive-free milled wood was extracted with $\mathrm{NaOH}$ solution at $0,3 \%(0,075 \mathrm{~mol} / \mathrm{L})$ for $1 \mathrm{~h}$ (liquid:wood ratio $50: 1)$ under nitrogen atmosphere for removal of tannins. Ten $g$ of extracted wood (dry basis) were placed in a 1-L three-necked flask fitted with a reflux condenser, nitrogen bubbler, and a dropping funnel. The solvent, $100 \mathrm{~mL}$ of dioxane/ water $(9: 1, \mathrm{v} / \mathrm{v})$ containing $1,82 \mathrm{~g} \mathrm{HCl}$ (equivalent to $0,2 \mathrm{M}$ ), was added slowly from the funnel. The mixture under nitrogen atmosphere was heated with a heating mantle and refluxed at $90-95^{\circ} \mathrm{C}$ for $40 \mathrm{~min}$. Then, the mixture was allowed to cool in nitrogen atmosphere until $50^{\circ} \mathrm{C}$. The liquid phase was decanted and the solid residue was extracted with $100 \mathrm{~mL}$ of acidic dioxane/water solution for $30 \mathrm{~min}$, as described above.

The procedure was repeated more two times. A fourth extraction was performed without addition of hydrochloric acid in the dioxane/water mixture. Each portion of extract was concentrated separately (from $200 \mathrm{~mL}$ to $40 \mathrm{~mL}$ ), the concentrates were combined and lignin was precipitated by addition of cold water in the dioxane solution. Filtered isolated lignin was extracted with diethyl ether $(100 \mathrm{~mL})$, then washed with water, and freeze-dried. Purity of lignin was determined using the methodology described by Dence (1992), where $2 \mathrm{mg}$ of lignin were introduced into tubes containing $5 \mathrm{~mL}$ of acetyl bromide, acetic acid $25 \% \mathrm{v} / \mathrm{v}$ and $0,2 \mathrm{~mL}$ of $70 \%$ perchloric acid. The samples were introduced in a water bath at $70^{\circ} \mathrm{C}$ for $30 \mathrm{~min}$ with occasional stirring. Subsequently, the digested sample was transferred to a $100 \mathrm{~mL}$ flask with $10 \mathrm{~mL} 2 \mathrm{M}$ $\mathrm{NaOH}$ and $25 \mathrm{~mL}$ of glacial acetic acid. The solution was made to a final volume of $100 \mathrm{~mL}$ with glacial acetic acid. Purity of lignin was determined by measuring the absorbance at $280 \mathrm{~nm}$, using $20,09 \mathrm{~L} / \mathrm{g} \mathrm{cm}$ as the absorptivity coefficient. Carbohydrates content of the lignins were determined by acid methanolysis according to Sundberg et al. (1996).

\section{Elemental and methoxyl analysis}

The amount of $\mathrm{C}, \mathrm{H}$ and $\mathrm{O}$ in the lignin samples was determined in an Elemental Analyser EA 1108 (FISONS Instrument). The methoxyl content in dioxane lignin was determined in accordance with methodology described by Li et al. (2012). Half milliliter hydroiodic acid (57\%) was mixed with $10 \mathrm{mg}$ of sample in headspace test vial, and then sealed with a septum. The vials were placed in an oil bath and heated for $30 \mathrm{~min}$ at $130^{\circ} \mathrm{C}$. The vials were cooled to room temperature, and $0,5 \mathrm{~mL} \mathrm{NaOH}(6 \mathrm{~mol} / \mathrm{L})$ was injected with a syringe into the sealed vial to neutralize the excess hydroiodic acid. The vial was immediately put into the headspace autosampler. All measurements were carried out using a TurboMatrix 40 Trap (Perkin Elmer) automatic headspace sampler and GC-MS 7890A-5975C (Agilent Technologies) with DB-5 capillary column (30 m x $0,25 \mathrm{~mm} \times 0.25 \mu \mathrm{m})$ at $40^{\circ} \mathrm{C}$, high-purity nitrogen carrier gas $1,0 \mathrm{~mL} / \mathrm{min}$ flow rate. Detector temperature was $280^{\circ} \mathrm{C}$ and headspace operating conditions were sample at $50^{\circ} \mathrm{C} ; 0,2$ min vial pressurization time and 0,3 min injection time. Standard deviation from a triplicate analysis was lower than $1 \%$. 


\section{Fourier-Transformed Infrared Spectroscopy (FTIR)}

FTIR spectra were recorded using a Perkin Elmer spectrometer model System 2000. The dried lignin samples from wood and pulp were embedded in $\mathrm{KBr}$ pellets in the concentration of $1 \mathrm{mg} / 100 \mathrm{mg} \mathrm{KBr}$. The spectra were recorded in transmittance mode in the range $4000-400 \mathrm{~cm}^{-1}$. The bands of each spectrum were assigned according to Pandey (1999), and lignin was classified according to Faix (1991).

\section{${ }^{31}$ P NMR spectroscopy}

The content of phenolic and aliphatic hydroxyl groups in the lignin structure was determined by phosphitylation of lignin samples according to Granata and Argyropoulos (1995). About $40 \mathrm{mg}$ of lignin was weighted and dissolved in $400 \mu \mathrm{L}$ of a solvent mixture of pyridine and deuterated chloroform $(1,6: 1)$. The samples were maintained at room temperature under constant stirring. Subsequently, it was added 100 $\mu \mathrm{L}$ cholesterol as internal standard and $50 \mu \mathrm{L}$ chromium (III) acetylacetonate as relaxation reagent. Finally, $100 \mu \mathrm{L}$ of 2-chloro-4,4,5,5-tetramethyl-1,3,2-dioxaphospholane (phophitylating reagent II). The ${ }^{31} \mathrm{P}$ NMR spectra were acquired using a BRUKER $400 \mathrm{MHz}$ spectrometer. The maximum standard error of the data was $1 \times 10^{-2} \mathrm{mmol} / \mathrm{g}$ lignin.

\section{Molar mass distribution}

Molar mass distribution of dioxane lignin was performed using the protocol described by Guerra et al. (2006). Lignin was acetylated with acetyl bromide before analysis. In a $15-\mathrm{mL}$ round bottom flask it was added $10 \mathrm{mg}$ of lignin and 2,5 mL of a mixture consisting of acetyl bromide and glacial acetic acid (8/92, $\mathrm{v} / \mathrm{v}$ ). The flask was sealed and placed in a water bath at $50^{\circ} \mathrm{C}$ for $2 \mathrm{~h}$ with continuous stirring. The solvent was evaporated in a rotary evaporator. The sample was immediately dissolved in THF and used for the size exclusion analysis. A size exclusion chromatography system (Waters) with UV detection was used. Analyses were performed at $40^{\circ} \mathrm{C}$, using tetrahydrofuran (THF) as eluent at $0,44 \mathrm{~mL} / \mathrm{min}$ and three Styragel columns mounted in series, HR1, HR3 and HR5 (Waters) with a mass range between (100 and $\left.4 \times 10^{-6} \mathrm{~g} / \mathrm{mol}\right)$. The GPC system was calibrated with polystyrene standards. Standard deviation for this analysis is lower than 5\%.

\section{RESULTS AND DISCUSSION}

Chemical composition of the six genotypes (Table 1) showed that G1 (samples 1, 2 and 3) contained the highest amount of glucans $(52,1 \%-53,8 \%)$ and the lowest amount of lignin $(23,8 \%-24,9 \%)$, whereas G2 (samples 4, 5 and 6) had lower glucans levels (48,7\%-50,3\%) and higher lignin contents (25,8\%-28,0\%). Kraft pulping of these genotypes was performed at $\mathrm{H}$-factor 800 and varied active alkali (AA) from $18,5 \%$ to $19,5 \%$ with the aim to prepare pulps with similar kappa number (16 \pm 1$)$. G1 samples presented higher pulp yields than samples from $\mathrm{G} 2$, which were related with their lower original lignin contents, higher proportion of S-type units and $\beta$-O-4 linkages, as previously reported by Aguayo et al. (2013). With the wood and pulp samples, dioxane lignin was prepared and used for a more detailed analysis of the lignin structure and to determine other possible features affecting pulp yield.

Dioxane lignin is frequently used for structural studies since its preparation allows good extraction yields with minimal structural changes during the procedure (Pascoal Neto et al. 1997, Evtuguin et al. 2001, Argyropoulos et al. 2002, Jahan and Mun 2007). The yield of dioxane lignin extracted from Eucalyptus globulus genotypes was calculated on the basis of the Klason lignin content and were in the range of $60 \%-71 \%$ for G1 and 47\%-56\% for G2. Residual lignins present in kraft pulps were also extracted, yielding around 44\% for G1 and $28 \%-36 \%$ for G2 pulps. The purity of the dioxane lignins extracted from wood and pulps varied between $88 \%$ and $99 \%$. Under the conditions used for lignin extraction, small amounts of carbohydrates from the lignin-carbohydrate complex (LCC) can also be extracted (Gellerstedt et al. 1994). The carbohydrates contents were quantified by acid methanolysis and revealed values up to $8 \%$ that were used to correct the results from the elemental analysis of the lignins (Jahan and Mun 2007). 


\section{Elemental analysis}

The empirical formula of the dioxane lignins from wood and pulps are shown in Table 2. The number of methoxyl groups per $\mathrm{C}_{9}$ unit in dioxane lignins from wood did not presented significant difference for G1 and G2 samples and was in the range of 1,3-1,5 methoxyl groups/ $\mathrm{C}_{9}$ units, as expected for Eucalyptus species (Pinto et al. 2002, Evtuguin and Pascoal Neto 2007). In pulps, the dioxane lignins from G1 samples presented 0,88-0,93 methoxyl groups $/ \mathrm{C}_{9}$ and 0,72-0,76 methoxyl groups $/ \mathrm{C}_{9}$ for $\mathrm{G} 2$. The demethoxylation degree in dioxane lignins from G2 was between $46 \%-51 \%$, higher than in G1, where demethoxylation was $30 \%-44 \%$. One on the reactions that occurs during kraft pulping is the cleavage of the methyl-aryl ether linkages in lignin. The primary reaction involves an attack of a hydrosulphide ion to the aromatic methyl ether group and formation of methylmercaptan together with a phenolic hydroxyl group (Gellerstedt 2009). A higher demethoxylation of lignin could increase the occurrence of condensation reactions decreasing the efficiency of lignin removal during kraft pulping.

Table 2. Empirical formula* of dioxane lignins isolated from wood and pulp of Eucalyptus globulus genotypes.

\begin{tabular}{|cccc|}
\hline Samples & & Wood lignin & Pulp lignin \\
\hline & 1 & $\mathrm{C}_{9} \mathrm{H}_{8,79} \mathrm{O}_{3,98}\left(\mathrm{OCH}_{3}\right)_{1,32}$ & $\mathrm{C}_{9} \mathrm{H}_{6,40} \mathrm{O}_{4,26}\left(\mathrm{OCH}_{3}\right)_{0,93}$ \\
$\mathrm{G} 1$ & 2 & $\mathrm{C}_{9} \mathrm{H}_{8,30} \mathrm{O}_{4,07}\left(\mathrm{OCH}_{3}\right)_{1,55}$ & $\mathrm{C}_{9} \mathrm{H}_{7,71} \mathrm{O}_{4,94}\left(\mathrm{OCH}_{3}\right)_{0,88}$ \\
& 3 & $\mathrm{C}_{9} \mathrm{H}_{8,62} \mathrm{O}_{3,99}\left(\mathrm{OCH}_{3}\right)_{1,45}$ & $\mathrm{C}_{9} \mathrm{H}_{7,53} \mathrm{O}_{3,91}\left(\mathrm{OCH}_{3}\right)_{0,91}$ \\
\hline & 4 & $\mathrm{C}_{9} \mathrm{H}_{7,80} \mathrm{O}_{4,88}\left(\mathrm{OCH}_{3}\right)_{1,56}$ & $\mathrm{C}_{9} \mathrm{H}_{8,66} \mathrm{O}_{3,48}\left(\mathrm{OCH}_{3}\right)_{0,76}$ \\
$\mathrm{G} 2$ & 5 & $\mathrm{C}_{9} \mathrm{H}_{8,16} \mathrm{O}_{4,23}\left(\mathrm{OCH}_{3}\right)_{1,34}$ & $\mathrm{C}_{9} \mathrm{H}_{8,89} \mathrm{O}_{3,31}\left(\mathrm{OCH}_{3}\right)_{0,72}$ \\
& 6 & $\mathrm{C}_{9} \mathrm{H}_{8,02} \mathrm{O}_{4,02}\left(\mathrm{OCH}_{3}\right)_{1,50}$ & $\mathrm{C}_{9} \mathrm{H}_{8,89} \mathrm{O}_{3,55}\left(\mathrm{OCH}_{3}\right)_{0,75}$ \\
\hline
\end{tabular}

* Empirical formula $\mathrm{CxHyOz}\left(\mathrm{OCH}_{3}\right) \mathrm{n}$ was calculated as: $\mathrm{n}=(\% \mathrm{OCH} 3) / 31,04 ; \mathrm{x}=(\% \mathrm{C}) / 12-\mathrm{n} ; \mathrm{y}=(\% \mathrm{H})-3 \mathrm{n}$; $z=(\% O) / 16-n($ Jahan and Mun 2007).

\section{Molar mass distribution}

The weight-average $(\mathrm{Mw})$, number-average $(\mathrm{Mn})$ molecular weight and polydispersity of dioxane lignins were obtained from GPC analysis (Figure 1). The data (Table 3) shows that the lignins isolated from wood samples had values of Mw between 9585-10802 $\mathrm{g} / \mathrm{mol}$ for G1 and between 11176-11527 g/mol of G2. For Mn the values were between 2439-3052 g/mol for G1 and between 2971-3928 g/mol for G2. Evtuguin et al. (2001), reported Mn value of 2180 for dioxane lignin extracted from Eucalyptus globulus. Nagy 2009, reported Mw $2400 \mathrm{~g} / \mathrm{mol}$ and Mn $2150 \mathrm{~g} / \mathrm{mol}$ for dioxane lignins of Eucalyptus spp. Dioxane lignins obtained from pulps had Mw values between 2508-2910 g/mol for G1 and between 2196-2858 g/mol for G2. For Mn the values for G1 were from 854 to $1122 \mathrm{~g} / \mathrm{mol}$ and from 671 to $717 \mathrm{~g} / \mathrm{mol}$ for G2. Similar values were reported for dioxane lignins extracted from Eucalyptus globulus kraft pulps (Pinto et al. 2002). 

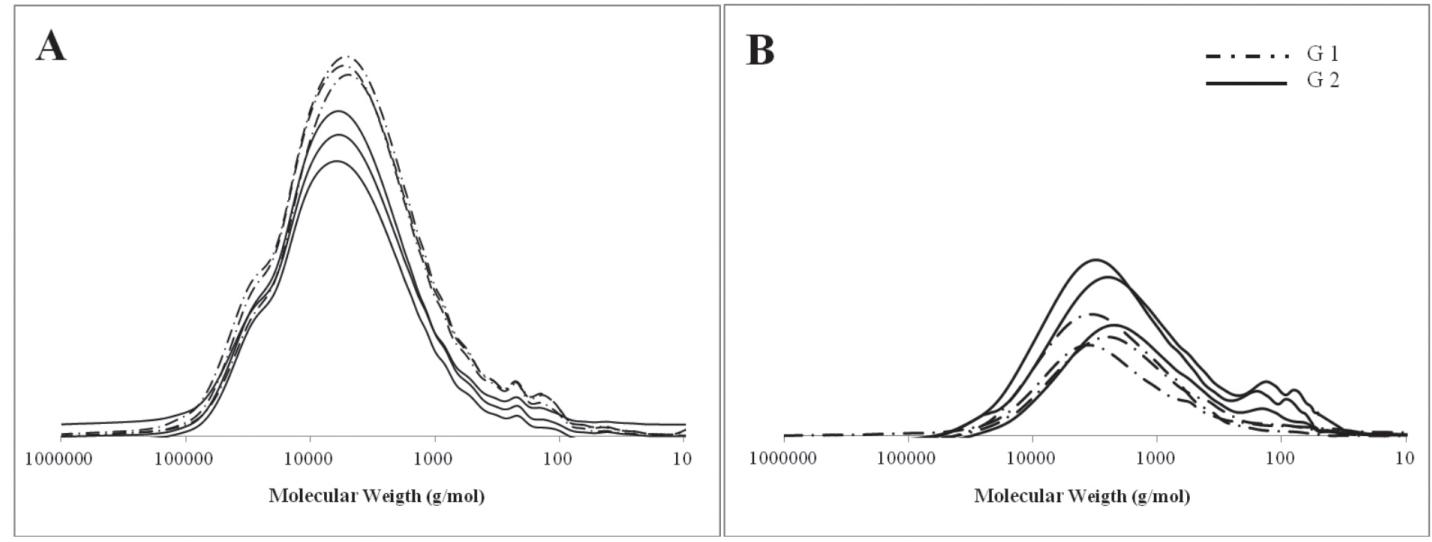

Figure 1. GPC chromatogram of dioxane lignins isolated from

(A) wood and (B) pulp of Eucalyptus globulus genotypes.

Table 3. Average molar masses of dioxane lignins extracted from wood and kraft pulps of Eucalyptus globulus genotypes.

\begin{tabular}{|c|c|c|c|c|c|c|c|}
\hline \multirow{2}{*}{\multicolumn{2}{|c|}{ Samples }} & \multicolumn{2}{|c|}{$\begin{array}{c}M w \\
(\mathrm{~g} / \mathrm{mol})\end{array}$} & \multicolumn{2}{|c|}{$\begin{array}{c}M n \\
(\mathrm{~g} / \mathrm{mol})\end{array}$} & \multicolumn{2}{|c|}{ D } \\
\hline & & wood & pulp & wood & pulp & wood & pulp \\
\hline \multirow{3}{*}{ G1 } & 1 & 10485 & 2907 & 3052 & 1122 & 3,4 & 2,6 \\
\hline & 2 & 10802 & 2910 & 2647 & 1084 & 4,1 & 2,7 \\
\hline & 3 & 9685 & 2508 & 2439 & 854 & 4 & 2,9 \\
\hline \multirow{3}{*}{$\mathrm{G} 2$} & 4 & 11315 & 2196 & 2980 & 680 & 3,8 & 3,2 \\
\hline & 5 & 11527 & 2858 & 3928 & 717 & 2,9 & 3,9 \\
\hline & 6 & 11176 & 2493 & 2971 & 671 & 3,8 & 3,7 \\
\hline
\end{tabular}

Standard deviation for $M w$ and $M n$ is lower than $5 \%$.

\section{FTIR}

FTIR spectra of dioxane lignins were shown in Figure 2 (Fig. 2A, wood lignin and Fig. 2B, pulp lignin). Band assignments were done according to Pandey (1999) and Faix (1991). All spectra showed absorbance bands at 1328 $\mathrm{cm}^{-1}$ (syringyl units) and a small shoulder at $1268 \mathrm{~cm}^{-1}$ (guaiacyl units), which is typical for hardwood lignins. Another characteristic of the lignins spectra is the band at $1462 \mathrm{~cm}^{-1}$ (C-H deformation, methyl and methylene) that was more intense than the band at $1505 \mathrm{~cm}^{-1}$ (aromatic skeletal vibration). The band at $1460 \mathrm{~cm}^{-1}$ indicates the $\mathrm{C}-\mathrm{H}$ vibration and deformation in the aromatic ring. The strong band intensity at $1124 \mathrm{~cm}^{-1}$ is associated with the structure of the syringyl lignin molecule. The FTIR analysis corroborated that the lignins isolated from wood and kraft pulps are GS4-type, according to the classification of Faix (1991). The presence of the band at $1720 \mathrm{~cm}^{-1}$ in dioxane lignins isolated from kraft pulps indicated an increase in the content of carbonyl groups from esters, aldehydes, or carbonyl groups non-conjugated with the aromatic ring (Faix 1992, Lin and Dence 1992). This is an indication that the increase in the content of carbonyl groups in the residual lignin is due to oxidation reactions that occurred during alkaline pulping (Rutkowska et al. 2009). 

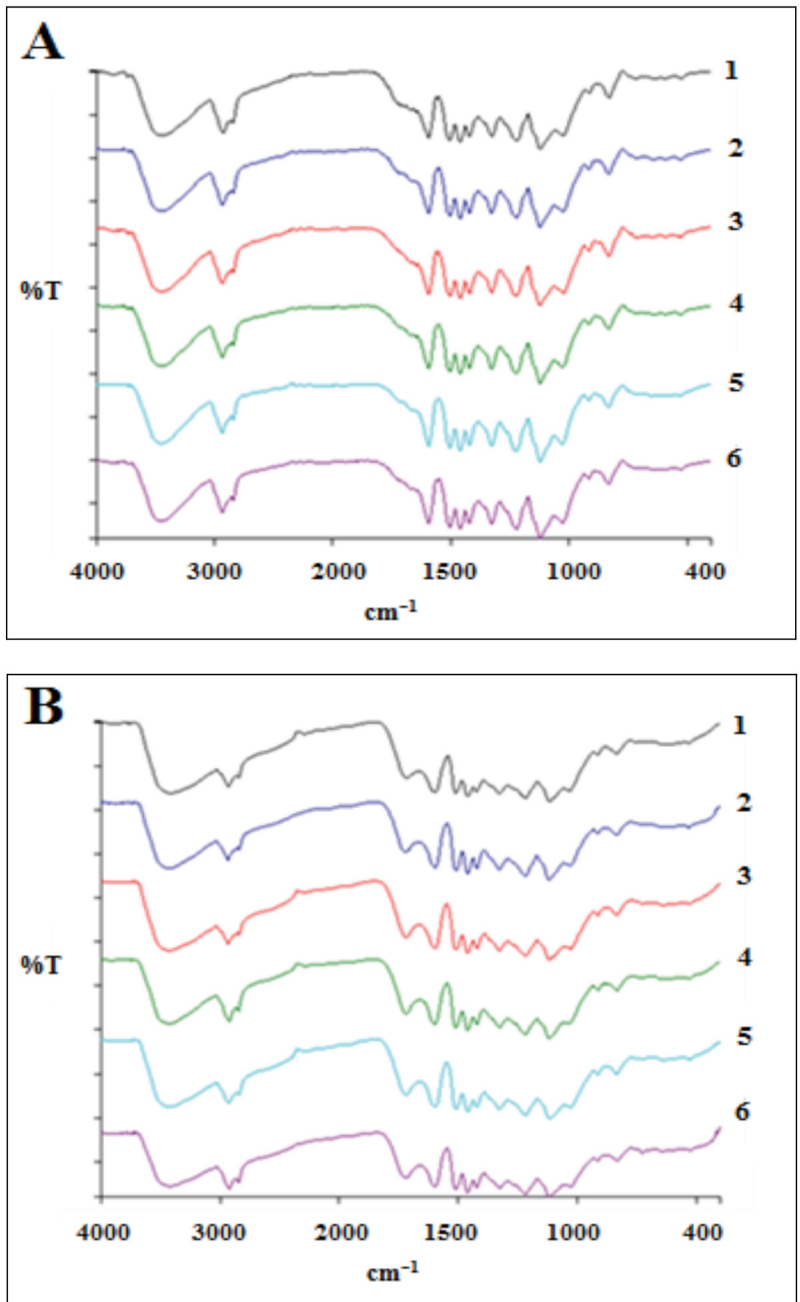

Figure 2. FTIR spectra of dioxane lignins isolated from (A) wood and (B) pulp. Samples 1, 2 and 3 corresponded to G1 and samples 4, 5 and 6 corresponded to G2.

\section{${ }^{31} \mathbf{P}$ NMR}

The lignins isolated from wood and pulps were subjected to ${ }^{31} \mathrm{P}$ NMR spectroscopy to determine the contents of phenolic and aliphatic hydroxyl groups associated with the lignin structure. A representative sample of the ${ }^{31} \mathrm{P}$ NMR is shown in figure 3. The integration zones for each structure were determined according to $\mathrm{Wu}$ and Argyropoulos (2003). The main structures with hydroxyl groups of the dioxane lignins determined by ${ }^{31} \mathrm{P}$ NMR were: OH-aliphatic, OH-syringyl (S-OH), OH-guaiacyl (G-OH), 5-5 biphenyl, OH-p-hydroxyl, $\mathrm{OH}-$ carboxyl and total phenolic hydroxyl $(\mathrm{Ph}-\mathrm{OH})$ groups. With $\mathrm{S}-\mathrm{OH}$ and $\mathrm{G}-\mathrm{OH}$ data, the syringyl/guaiacyl ratio was calculated (Table 4). The pulp yield was used as a ranking parameter and correlated with the lignin structural traits (Figure 4). 


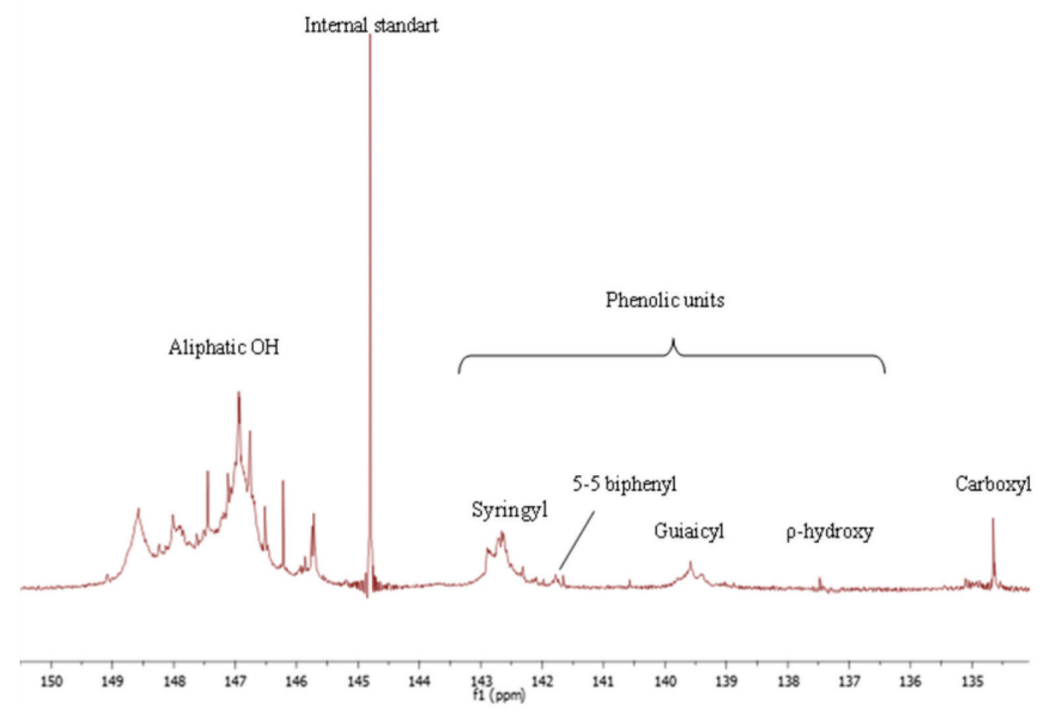

Figure 3. ${ }^{31} \mathrm{P}$ NMR spectrum representative for Eucalyptus globulus dioxane lignin (genotype 1).

Table 4. Hydroxyl groups (determined by ${ }^{31} \mathrm{P} N \mathrm{NM}$ ) and $\mathrm{S} / \mathrm{G}$ ratio in dioxane lignins isolated from wood and pulps of Eucalyptus globulus genotypes.*

\begin{tabular}{|c|c|c|c|c|c|c|c|c|c|}
\hline \multicolumn{10}{|c|}{ Structures (mmol/g of lignin) } \\
\hline & & $\begin{array}{c}\mathrm{OH} \\
\text { aliphatic }\end{array}$ & $\begin{array}{c}\mathrm{OH} \\
\text { syringyl }\end{array}$ & $\begin{array}{c}5-5 \\
\text { biphenyl }\end{array}$ & $\begin{array}{c}\mathrm{OH} \\
\text { guaiacyl }\end{array}$ & $\begin{array}{c}\text { OH } \\
\rho \text {-hydroxyl }\end{array}$ & $\begin{array}{c}\mathrm{OH} \\
\text { carboxyl }\end{array}$ & $\begin{array}{c}\text { Total } \\
\text { phenolic } \mathrm{OH}\end{array}$ & $\begin{array}{l}\mathrm{S} / \mathrm{G} \\
\text { ratio }\end{array}$ \\
\hline \multicolumn{2}{|c|}{$\begin{array}{l}\text { Integration limits } \\
(\mathrm{ppm})\end{array}$} & $146,6-150$ & $143,4-142,4$ & $141,7-142,3$ & $139,2-140,2$ & $137-138$ & $134,7-135$ & & \\
\hline \multirow{6}{*}{$\begin{array}{l}\text { Wood } \\
\text { lignin }\end{array}$} & 1 & 4,48 & 0,73 & 0,10 & 0,22 & 0,02 & 0,08 & 1,07 & 3,4 \\
\hline & 2 & 3,91 & 0,72 & 0,11 & 0,22 & 0,03 & 0,03 & 1,08 & 3,3 \\
\hline & 3 & 4,48 & 0,64 & 0,09 & 0,19 & 0,05 & 0,01 & 0,97 & 3,3 \\
\hline & 4 & 3,81 & 0,58 & 0,14 & 0,25 & 0,02 & 0,01 & 1 & 2,3 \\
\hline & 5 & 4,05 & 0,58 & 0,13 & 0,25 & 0,01 & 0,01 & 0,98 & 2,3 \\
\hline & 6 & 4,11 & 0,59 & 0,14 & 0,29 & 0,01 & 0,01 & 1,03 & 2 \\
\hline \multirow{6}{*}{ Pulp lignin } & 1 & 2,77 & 0,68 & 0,31 & 0,26 & 0,06 & 0,22 & 1,31 & 2,6 \\
\hline & 2 & 2,05 & 0,62 & 0,30 & 0,25 & 0,04 & 0,20 & 1,21 & 2,5 \\
\hline & 3 & 2,47 & 0,70 & 0,30 & 0,26 & 0,05 & 0,13 & 1,31 & 2,7 \\
\hline & 4 & 1,89 & 0,50 & 0,36 & 0,25 & 0,05 & 0,14 & 1,16 & 2 \\
\hline & 5 & 2,25 & 0,49 & 0,33 & 0,24 & 0,05 & 0,15 & 1,11 & 2 \\
\hline & 6 & 1,95 & 0,47 & 0,38 & 0,21 & 0,04 & 0,19 & 1,10 & 2,2 \\
\hline
\end{tabular}

* The maximum standard error of the data was $1 \times 10^{-2} \mathrm{mmol} / \mathrm{g}$ lignin. 
High correlations were found for pulp yield vs. S-OH, (Fig. 4A), pulp yield vs. S-OH/G-OH ratio, (Fig. 4B) and pulp yield $v s$. 5-5 biphenyl, (Fig. 4D). Low correlation was found for pulp yield vs. G-OH units (Fig. 4C). High syringyl contents, as well as, high $\mathrm{S} / \mathrm{G}$ ratio favored the lignin removal during kraft pulping promoting a faster delignification and less recondensation at the ending of the pulping (Sjöström 1993, Gellerstedt 2009). Regarding the condensed structures, the 5-5 biphenyl units are presented in smaller amounts in wood, however, have a negative correlation with the pulp yield (Fig. 4D) since decreased the delignification rate hindering lignin fragmentation (Sjöström 1993, Gellerstedt 2009). The total phenolic hydroxyl groups of dioxane lignins presented a poor correlation with pulp yield (data not showed), same behavior was reported by Guerra et al. (2008).

Kraft delignification occurs by modifying the structure of lignin mainly in two ways, the first mechanism is the degradation of lignin by cleaving interunits linkages by means of hydroxy and hydrosulfite anions, while the second is the introduction of hydrophilic groups making the degradation products more soluble in the cooking liquor (Sjöström 1993). These phenomena generated new free phenolic hydroxyl groups, as observed in the isolated lignin from pulp, when compared with lignins from wood (Table 4). Prinsen et al. (2013), indicated that a high content of phenolic hydroxyl groups in dioxane lignin in pulps is the result of high levels of $\beta-\mathrm{O}-4$ bonds in wood lignin. This tendency is also observed in the Eucalyptus globulus genotypes of the present study as shown in figure $5(\mathrm{r}=0,92 ; \mathrm{p}=0,008)$.

In lignins extracted from pulps it was observed an increase in the content of 5-5 biphenyl units that could be the responsible for the low yields of extraction with dioxane. Furthermore, the content of 5-5 biphenyl structures in residual lignin could also be associated with the content of G-units in lignin from wood, generating more condensed units during pulping. These results were also in agreement with the previously obtained (Aguayo et al. 2013), where samples from G2 showed an increase in the UV absorbance during the topochemical study of delignification. Furthermore, the increase of condensed structures in the residual lignin could also have an effect on the subsequent bleaching process, as observed by Pinto et al. (2005).

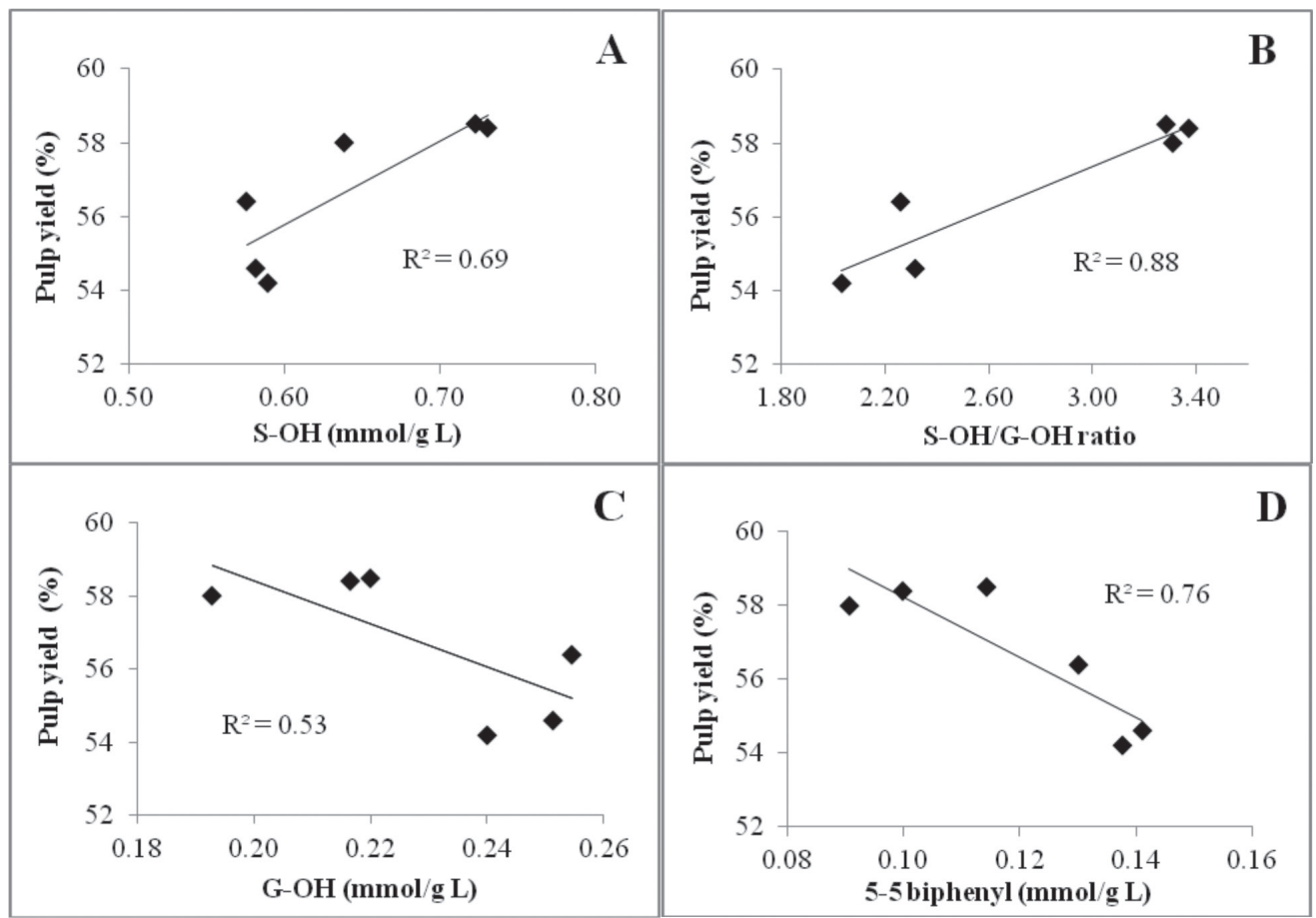

Figure 4. Relationship between pulp yield and (A) S-OH, (B) S/G ratio, (C) G-OH and (D) 5-5 biphenyl units of dioxane lignins isolated from Eucalyptus globulus wood. The maximum standard error for pulp yield is $0,5 \%$ and for lignin features is lower than $1 \times 10^{-2} \mathrm{mmol} / \mathrm{g}$ lignin. 


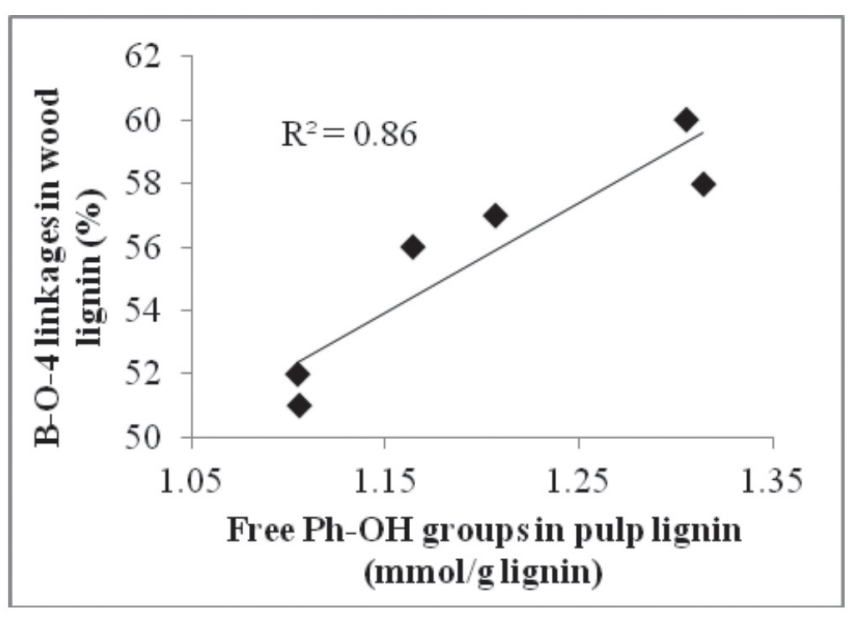

Figure 5. Relationship between $\beta-O-4$ linkages in lignin from wood and free phenolic hydroxyl groups in lignin from kraft pulps of Eucalyptus globulus genotypes. The maximum standard error for B-O-4 linkages is $3 \%$ and for free $\mathrm{OH}$ groups is lower than $1 \times 10^{-2} \mathrm{mmol} / \mathrm{g}$ lignin.

\section{CONCLUSIONS}

The analysis of dioxane lignins isolated from wood and kraft pulps of Eucalyptus globulus genotypes revealed structural features of the macromolecule that contributed to explain the contrasting pulpwood characteristics. The main structures that differentiated the two groups and with high correlation with the pulp yield were the content of S-units and S/G ratio. More condensed units (5-5 biphenyl) had a negative impact on pulp yield. These results showed that the structure of lignin in genotypes of a single species also plays a key role in pulp yield and should be considered as a parameter for the selection and improvement of the species in commercial plantations for pulp production.

\section{ACKNOWLEDGEMENTS}

FONDECYT (grant 1110828) and MECESUP (grant UCO 0702). 


\section{REFERENCES}

Aguayo, M.G.; Ferraz, A.; Elissetche, J.; Masarin, F.; Mendonça R.T. 2013. Lignin chemistry and topochemistry durin kraft delignification of Eucalyptus globulus genotypes with contrasting pulpwood characteristics. Holzforschung 68:623-629.

Argyropoulos, D.S.; Sun, Y.; Palus, E. 2002. Isolation of residual kraft lignin in high yield and purity. J Pulp Paper Sci 28:50-54.

Dence, C.W. 1992. The determination of lignin. In: Lin SY. Dence CW (eds) Methods in Lignin Chemistry. Springer, Berlin, pp 33-61.

Evtuguin, D.V.; Pascoal Neto, C.; Silva, A.; Domingues, P.M.; Amado, F.M.L.; Robert, D.; Faix, O. 2001. Comprehensive study on the chemical structure of dioxane lignin from plantation Eucalyptus globulus wood. J Agric Food Chem 49:4252-4261.

Evtuguin, D.V; Pascoal Neto,C. 2007. Recent advances in eucalyptus wood chemistry: Structural features through the prism of technological response. In: $3^{\text {th }}$ International Colloquium on Eucalyptus Pulp. Belo Horizonte, Brasil.

Faix, O. 1991. Classification of lignin from different botanical origins by FT-IR Spectroscopy. Holzforschung 45:21-27.

Faix, O. 1992. Fourier transform infrared spectroscopy. Methods in Lignin Chemistry. S. Y. Lin and C. W. Dence (eds.), Springer-Verlag, Berlin Heidelberg. pp 83-109.

Gellerstedt, G. 2009. Chemistry of Bleaching of Chemical Pulp. In Pulp and Paper Chemistry and Technology Vol 2; Ek, M.; Henriksson, G., Eds.; De Gruyter, Inc.; Germany, pp 97-104.

Gellerstedt, G.; Pranda, J.; Lindfors, E.L. 1994. Structural and molecular properties of residual birch kraft lignins. $J$ Wood Chem Technol 14:467-482.

Granata, A.; Argyropoulos, D.S. 1995. 2-Chloro-4,4,5,5-tetramethyl-1,3,2-dioxaphospholate, a reagent for the accurate determination of the uncondensed and condensed phenolic moieties in lignins. J Agric Food Chem 43:1538.

Guerra, A.; Filpponen, I.; Lucia, L.A.; Argyropoulos, D.S. 2006. Comparative evaluation of three lignin isolation protocols for various wood species. J Agric Food Chem 54:9696-9705.

Guerra, A.; Elissetche, J.; Norambuena, M.; Freer, J.; Valenzuela, J.; Rodríguez, J.; Balocchi, C. 2008. Influence of lignin structural on Eucalyptus globulus kraft pulping. J Agric Food Chem 47:8542-8549.

Jahan, M.S.; Mun, S.P. 2007. Characteristics of dioxane lignins isolated at different ages of Nalita wood (Trema orientalis). J Wood Chem Technol 27:83-98.

Li, H.; Chai, X.; Liu, M.; Deng, Y. 2012. Novel method for the determination of the methoxyl content in lignin by headspace Gas Chromatography. J Agric Food Chem 60:5307-5310.

Lin, S. Y.; and Dence, C. W. 1992. Fourier transform infrared spectroscopy. Methods in Lignin Chemistry. S. Y. Lin and C. W. Dence (eds.), Springer-Verlag, Berlin Heidelberg. p 96. 
Nagy, M. 2009. Biofuels from lignin and novel biodiesel analysis. Tesis Doctor of Philosophy in the School of Chemistry and Biochemistry, Georgia Institute of Technology.

Pandey, K.K. 1999. A study of chemical structure of soft and hardwood and wood polymers by FTIR Spectroscopy. J Applied Polymer Sci 71:1969-1975.

Pascoal Neto, C.; Evtuguin, D. V.; Paulino, P. P. 1997. Effect of polyphenolic extractives on the quantification and structural characterization of the Eucalyptus globulus lignin. In Proc. of $9^{\text {th }}$ ISWPC, Montreal, pp 78.1-78.4.

Pinto, P.; Evtuguin, D.; Pascoal Neto, C.; Silvestre, A. 2002. Behavior of Eucalyptus globulus lignin during kraft pulping. I Analysis by chemical degradation methods. J Wood Chem Technol 22:93-108.

Pinto, P.C.; Evtuguin, D.V.; Pascoal Neto, C.P. 2005. Effect of structural features of wood biopolymers on hardwood pulping and bleaching performance. Ind Eng Chem Res 44:9777-9784.

Prinsen, P.; Rencoret, J.; Gutiérrez, A.; Liitia, T.; Tamminen, T.; Colodette, J.; Berbis, M.; JiménezBarbero, J.; Martinez, A.; Del Rio, J. 2013. Modification of the lignin structure during alkaline delignification of Eucalyptus wood by kraft, Soda-AQ, and Soda-O Cooking. Ind Eng Chem Res 52:15702-15712.

Ramirez, M.; Rodríguez, J.; Balocchi, C.; Peredo, M.; Elissetche, J.P.; Mendonça, R.; Valenzuela, S. 2009. Chemical composition and wood anatomy of Eucalyptus globulus clones: variations and relationships with pulpability and handsheet properties. J Wood Chem Technol 29:43-58.

Rutkowska, E.; Wollboldt, P.; Zuckerstätter, G.; Weber, H.K.; Sixta, H. 2009. Characterization of structural changes in ligninduring continuous batch kraft cooking of Eucalyptus globulus. BioResources 4:172-193.

Sjöström, E. 1993. Wood Chemistry: Fundamentals and Applications. New York, Academic Press, p. 293.

Sundberg, A.; Sundberg, K.; Lillandi, C.; Holmbom, B. 1996. Determination of hemicelluloses and pectins in wood and pulp by acid methanolysis and gas chromatography. Nordic Pulp Paper Res J11: 216-226.

Wu, S.; Argyropoulos, D. 2003. An improved method for isolating lignin in high yield and purity. $J$ Pulp Pap Sci 29:235-240. 